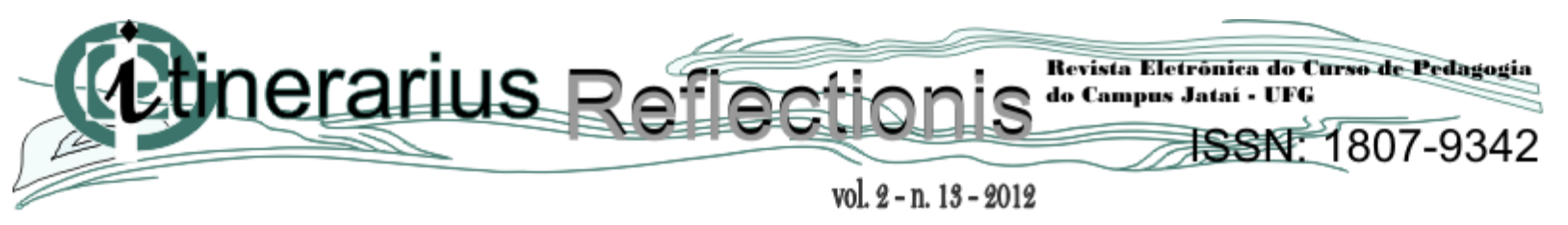

\title{
O PROEJA E O PERFIL DE SEUS ALUNOS NO CURSO TÉCNICO DE EDIFICAÇÕES
}

\author{
Luciana Cândido e Silva \\ lucianacandido26@yahoo.com.br \\ Paulo Henrique de Souza \\ phsouzas@yahoo.com.br \\ Instituto Federal de Goiás - Câmpus Jataí
}

RESUMO: Esse artigo apresenta o resultado de uma pesquisa documental desenvolvida no Instituto Federal de Educação Ciência e Tecnologia de Goiás - Campus Jataí, que visa a analisar as características sociais e econômicas dos alunos do Programa Nacional de Educação Profissional Integrada à Educação Básica na Modalidade da Educação de Jovens e Adultos (PROEJA). O objetivo foi traçar o perfil dos alunos e levantar as possíveis causas dos índices de evasão no curso. A pesquisa foi realizada em documentos institucionais de campus entre os anos de 2009 e 2012. Foi verificado que 56\% dos alunos são do sexo masculino, $62 \%$ dos alunos são solteiros, $45 \%$ estão entre 20 e 29 anos e $33 \%$ estão entre 30 e 39 anos, $72 \%$ são jovens e adultos trabalhadores e que a renda familiar de $48 \%$ dos alunos está entre 1 e 2 salários mínimos e $31 \%$ entre 2 e 3 salários. Assim, são cidadãos de baixa renda que buscam um ensino de qualidade e que ofereça oportunidade de bom emprego ao final do curso com o objetivo de melhorarem a renda familiar. Os índices de evasão nas turmas com ingresso em 2011 foi de aproximadamente 50\%, nos últimos períodos há índices de evasão superior a $60 \%$.

Palavras-Chave: PROEJA. Evasão. Perfil Socioeconômico.

\section{THE PROEJA AND PROFILE OF STUDENTS IN THEIR COURSE TECHNICAL BUILDING}

\begin{abstract}
This is Article introduce the result in the a search documental developed in the Institute Federal Of Education, Science And Technology of Goiás - Unit Jataí that vise technology analyze the feature social and economics of the pupils the Program National of the Education Basic in the Modality of the Education of the Young is trace the profile of the pupils the joined this lift the possible reasons of the index of the escape in the course. The search realized in documents of the institution of the unit among the years 2009 and 2012. Went exam mined that $56 \%$ of the pupils are masculine sex, $62 \%$ in the pupils are unmarried, 45\% are among 20 and 29 years old. $72 \%$ are young and adults workers that the family net income of $48 \%$ of the pupils is between 2 and 3 salaries. So, are citizen of low income that look for a teaching of quality and that offer opportunity of good employ in the finish. Of
\end{abstract}


course with the objective in the improve the family rent.

The index of escapes in the group with enter at 2011 went in the approximation $50 \%$ in the last period found index of escape higher the $60 \%$.

Key-words: PROEJA. Escape. Profile Economic Partner.

\section{Introdução}

Este artigo apresenta um curto histórico da implantação do Programa Nacional de Educação Profissional Integrada à Educação Básica na Modalidade da Educação de Jovens e Adultos (PROEJA) no país, descreve a implantação do curso técnico integrado de Edificações no antigo Centro Federal de Educação, Ciência e Tecnologia de Goiás - Unidade Descentralizada de Jataí (CEFET-GO/UnED Jataî) e realiza uma análise dos dados do curso entre os anos de 2009 e 2012, os quais foram coletados na própria instituição que passou a ser designada como Instituto Federal de Educação Ciência e Tecnologia de Goiás - Câmpus Jataí (IFG - Câmpus Jataí). O principal objetivo foi traçar o perfil dos alunos e levantar as possíveis causas dos índices de evasão no curso e ainda promover uma reflexão sobre a implantação do PROEJA no câmpus, e analisar os aspectos socioeconômicos e educacionais vinculados à formação dos alunos. Os resultados apresentados e discutidos neste artigo devem servir como mapeamento dos principais desafios para o êxito e permanência dos alunos do PROEJA na instituição.

Esta pesquisa é de natureza documental, realizada a partir de documentos, contemporâneos ou retrospectivos, considerados cientificamente autênticos, tendo como objeto de estudo a pasta de matrículas dos alunos de todos os períodos do curso PROEJA, o projeto pedagógico do curso, além de documentos referentes à criação do curso no Brasil como o Decreto $\mathrm{n}^{\mathrm{o}} 5.840$, de 13 de julho de 2006. No total foram analisadas 84 pastas, que são referentes a alunos matriculados em cinco períodos diferentes do curso e que mostram sua situação socioeconômica, além de sua situação frente às disciplinas cursadas. 


\section{(1Etinerarius Reflectionis:}

Fundamentação teórica

O Programa Nacional de Educação Profissional Integrada à Educação Básica na Modalidade da Educação de Jovens e Adultos (PROEJA)

O Programa Nacional de Educação Profissional Integrada à Educação Básica na Modalidade de Jovens e Adultos tem suas bases lançadas no Decreto n ${ }^{\circ} 5154$ de 23 de julho de 2004, sendo instituído pelo Decreto $\mathrm{n}^{\circ}$ 5840/2006, tais documentos orientam, em um contexto de embates, pela superação da histórica dicotomia entre formação profissional e educação geral. O documento base do PROEJA destaca que esse projeto educacional:

\footnotetext{
como fundamento a integração entre trabalho, ciência, técnica, tecnologia, humanismo e cultura geral com a finalidade de contribuir para o enriquecimento científico, cultural, político e profissional como condições necessárias para o efetivo exercício da cidadania. (BRASIL, 2007)
}

A educação de jovens e adultos tem como objetivo atender o direito do cidadão à educação, estabelecido na Constituição Federal vigente. A parcela da população atendida por esta modalidade de ensino, por algum motivo, não conseguiu dar continuidade a sua formação básica e normalmente estão marginais ao sistema atuando em subempregos, empregos informais ou ainda desempregados. Assim, foi necessária uma política pública que trate deste problema enfrentando a baixa expectativa de inclusão destes jovens e adultos no sistema público de educação profissional. O combate à desigualdade social tem sido o lema do Governo Federal nas últimas gestões, com políticas de inclusão, que constituem ações que envolvem a educação integral do cidadão, buscando a educação profissional com incentivos à elevação de escolaridade. (Brasil, 2007)

Neste contexto, como afirma Frigotto, 


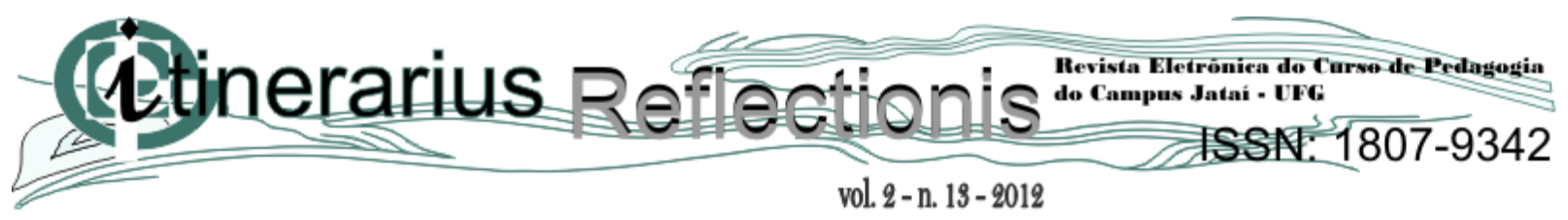

A educação escolar básica - ensino fundamental e médio - tem uma função estratégica central dentro da construção de uma nação no seu âmbito cultural, social, político e econômico e, condição, para uma relação soberana e, portanto, não subalterna e colonizada com as demais nações. (FRIGOTTO, 2008, p.10).

Desta forma, as discussões e contradições entre a formação com elevação de escolaridade e a formação profissional, focada na dinâmica do mercado, passam a ser tratadas, como destaca Castro (2010):

Essas configurações já indicam, por um lado, dois fundamentos que vão acompanhar a construção da história da rede federal: o primeiro, a forte relação entre educação profissional e demanda dos setores produtivos, e o segundo, a sua destinação aos filhos dos trabalhadores, cuja formação deve estar voltada para o trabalho de pouca complexidade e ser tomada como de "segunda classe". Este último revela, mais uma vez, a correspondência entre a estrutura dual da sociedade e a estrutura dual da educação, condição que tem resguardado uma formação geral (propedêutica) para as elites e uma formação prática (profissional) para os trabalhadores. (CASTRO, 2010, p.26).

Além disso, não podemos deixar de destacar neste debate princípios constitucionais que, como reforça Castro (2010):

Trata-se, além disso, do resultado de uma confluência de esforços que se fizeram presentes no âmbito do governo federal, desde o início do governo Lula, para dar respostas às demandas e pressões da sociedade civil na garantia da educação como um direito de todos. (CASTRO, 2010, p.27).

Com isto, há uma configuração nova com outros enfrentamentos no campo dos currículos e nas diretrizes da educação profissional e ensino médio. O PROEJA nas instituições públicas federais deve agora atender a uma demanda de um público que normalmente não estava presente entre seu público da instituição, o que leva a tensões e questionamentos na comunidade interna sobre sua viabilidade e capacitação no trabalho nesta modalidade de ensino.

O Decreto $\mathrm{n}^{\circ} 5154 / 2004$, que regulamenta os artigos relacionados à educação profissional da Lei 9.394/1996, por si só, não foi capaz de superar os problemas da qualificação profissional promovido pelo ensino profissionalizante em nosso país. Este decreto sinaliza a possibilidade da educação integrada, mas o governo não teve muitos 
esforços em instituí-la nos estabelecimentos públicos em âmbitos federal, estadual e municipal, ampliando as matrículas para o ensino médio e elevando sua qualidade. Além disso, a própria população não se mobilizou e não se apropriou do decreto como instrumento de mudanças efetivas em relação à educação profissional.

O Programa Nacional de Integração da Educação Profissional com a Educação Básica na Modalidade de Educação de Jovens e Adultos (PROEJA) se deu um ano depois, a partir de 2005 com a Portaria do Ministério da Educação n 2080, a qual estabeleceu diretrizes para a oferta de educação profissional integrada com o ensino médio na modalidade de educação de jovens e adultos. A partir dessa data iniciou-se intensa discussão através de fóruns de debates com todas as áreas envolvidas no projeto. Porém a não aceitação desse programa por alguns Centros Federais de Educação Tecnológica, Escolas Agrotécnicas Federais e Escolas Técnicas Federais, nos moldes como foi formulado, obrigou o governo Federal a rever o PROEJA. Foi a partir dessas discussões que o Governo Federal regulariza essa nova modalidade de ensino, com o Decreto n ${ }^{\circ} 5840 / 2006$ que diz que toda rede pública de ensino e sistema $\mathrm{S}$ - e mantendo a obrigatoriedade para a rede tecnológica federal de ensino - terão a possibilidade de ofertar cursos na modalidade PROEJA com incentivo financeiro já em 2007 com aproximadamente 22 milhões de reais, sendo que a primeira proposta implantada foi a de desenvolvimento profissional de professores e gestores para atuar nessa modalidade através de cursos de especialização em PROEJA e a criação do núcleo de pesquisa sobre PROEJA.

Desse modo, o PROEJA surge como um novo recurso para formação profissional dos indivíduos que, de uma forma ou de outra não tiveram a oportunidade da escolarização na idade regular, além de promover a educação de jovens e adultos como modalidade de ensino respeitada e valorizada pelo governo.

Assim, com o decreto $n^{\circ}$ 5840/2006, já a partir de 2007, todos os CEFETs já seriam obrigados a implantar o programa PROEJA em sua instituição, oferecendo pelo menos $10 \%$ de seu total de vagas para os referidos cursos dessa modalidade. 


\section{C(citinerarius Reflectionis: $=$ \\ O PROEJA no Instituto Federal de Educação Ciência e Tecnologias de Goiás - Campus Jataí}

O Instituto Federal de Educação Ciência e Tecnologia de Goiás - Campus Jataí oferece o curso técnico integrado em Edificações na modalidade PROEJA desde o ano de 2006, no período noturno e seu projeto pedagógico define uma organização semestral, com duração mínima de 8 semestres, ou seja, 4 anos. Inicialmente o curso era ofertado com ingresso anual, sendo ofertadas 40 vagas por ano. Em 2010 o ingresso também foi anual, mas foram ofertadas 30 vagas. Já em 2011 e 2012 o ingresso foi semestral com 30 vagas, perfazendo um total de 60 vagas ofertadas no ano.

O processo seletivo para o PROEJA é distinto dos demais cursos técnicos e superiores da instituição, pois não há uma prova de conhecimentos. A seleção acontece por meio de uma chamada pública e a classificação dos alunos atende aos critérios de ordem de inscrição, participação em palestra e em entrevista. Podem participar do processo alunos com idade mínima de 18 anos que não tenham concluído o ensino médio e que possuem certificado de conclusão do ensino fundamental.

No início da implantação do curso ocorreu uma parceria com a Secretaria da Educação do Estado de Goiás e parte dos professores das disciplinas do núcleo comum eram professores cedidos pela Secretaria. No primeiro semestre de 2010 esta situação foi alterada e todos os professores do curso passaram a ser do quadro federal, esta ação buscava uma interação maior entre os professores do curso.

No projeto pedagógico do curso, elaborado no final de 2005, a Unidade de Jataí oferecia o curso técnico subsequente em Edificações, para alunos com ensino médio completo e já havia oferecido o curso técnico de Edificações, junto com a formação em ensino médio, o que foi extinto após o Decreto n. 2208de 17 de abril de 1997. Assim, baseados no Decreto 5154/04, nos referenciais curriculares nacionais da educação profissional de nível técnico, nas diretrizes curriculares nacionais para o ensino médio, na Lei de Diretrizes e Bases da Educação Nacional (LDB 9394/96) e no Projeto Pedagógico do CEFET-GO, foram elaborados a organização curricular do curso técnico de nível médio integrado em Edificações na modalidade PROEJA. 


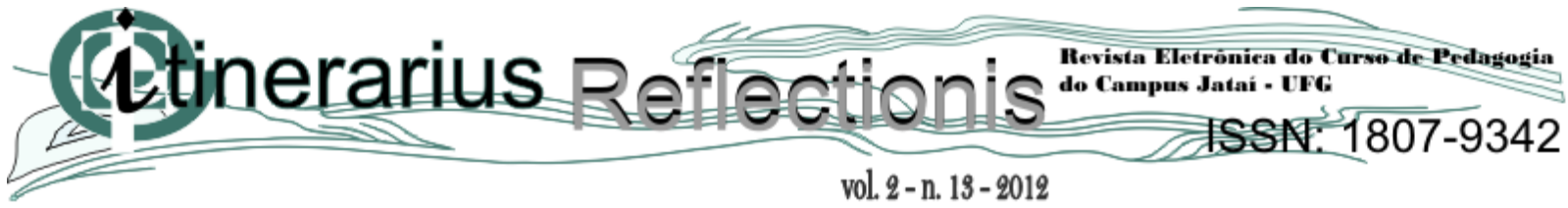

A matriz do curso está organizada em três partes: um núcleo comum, o qual é composto por disciplinas das três áreas de conhecimento definidas nas diretrizes curriculares nacionais para o ensino médio; uma parte diversificada, a qual é composta por disciplinas voltadas para as relações existentes no mundo do trabalho e sua articulação com os conhecimentos escolares; e uma parte de formação profissional, a qual é composta pelas disciplinas específicas da área de edificações. Como pode-se observar na matriz, quadro 1 , existem disciplinas da parte profissional desde o início do curso.

Quadro 1 - Matriz Curricular do Curso Técnico Integrado de Nível Médio em Edificações na Modalidade PROEJA do IFG - Câmpus Jataí.

\begin{tabular}{|c|c|c|c|c|c|c|c|c|c|c|c|c|c|}
\hline \multicolumn{14}{|c|}{$\begin{array}{l}\text { MATRIZ CURRICULAR DO CURSO DE EDUCAÇAO PROFISSIONAL TECNICA DE NIVEL } \\
\text { MEDIO DA AREA DE CONSTRUÇAO CIVIL MODALIDADE PROEJA - CEFET-GO/Jataf }\end{array}$} \\
\hline \multirow{3}{*}{\multicolumn{2}{|c|}{ AREAS }} & \multirow{3}{*}{ DISCIPLINAS } & \multicolumn{8}{|c|}{ CARGA HORARIA SEMANAL } & \multirow{3}{*}{$\begin{array}{l}\frac{1}{2} \\
\frac{3}{3} \\
\frac{3}{5} \\
\frac{1}{2} \\
5 \\
2\end{array}$} & \multirow{3}{*}{ 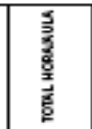 } & \multirow{3}{*}{ 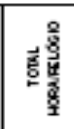 } \\
\hline & & & \multicolumn{2}{|c|}{$1^{\circ}$ ANO } & \multicolumn{2}{|c|}{$\approx A N O$} & \multicolumn{2}{|c|}{ 3. ANO } & \multicolumn{2}{|c|}{ 4* ANO } & & & \\
\hline & & & SÉM & SËM & \begin{tabular}{|l|}
3 \\
SEM
\end{tabular} & SEM & SÉM & SEM & SÉM & SEM & & & \\
\hline \multirow{10}{*}{ 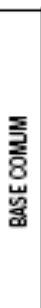 } & \multirow{2}{*}{ 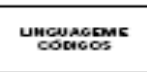 } & $\begin{array}{l}\text { Lingus Portoguess e Ltershura } \\
\text { Brasleirs }\end{array}$ & $=$ & $=$ & $=$ & $=$ & $=$ & 2 & $=$ & $=$ & 16 & 320 & 240 \\
\hline & & \begin{tabular}{|l|l|} 
Artes \\
\end{tabular} & - & - & 2 & - & - & - & - & - & 2 & 40 & 30 \\
\hline & \multirow{4}{*}{ 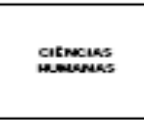 } & Geogratia & - & - & 2 & 2 & - & - & - & - & 4 & 80 & 60 \\
\hline & & 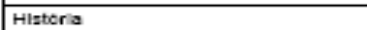 & - & - & - & - & 2 & 2 & - & - & 4 & 80 & 60 \\
\hline & & Fliosong & - & - & 2 & - & - & - & - & - & 2 & 40 & 30 \\
\hline & & Soclalogla & - & - & - & 2 & - & - & - & - & 2 & 40 & 30 \\
\hline & \multirow{4}{*}{ 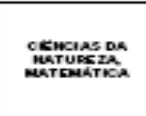 } & \begin{tabular}{|l|l|l|l|} 
Flaka \\
\end{tabular} & 4 & 4 & 4 & 2 & - & - & - & - & 14 & 280 & 210 \\
\hline & & Matemstica & 4 & 4 & 4 & 4 & - & - & - & - & 16 & 320 & 240 \\
\hline & & Quimica & 2 & 2 & 2 & 2 & - & - & - & - & 8 & 160 & 120 \\
\hline & & Elologa & 2 & 2 & - & - & - & - & - & - & 4 & ao & 60 \\
\hline & \multicolumn{2}{|c|}{ SUB-TOTAL } & 14 & 14 & 18 & 14 & 4 & 4 & 2 & 2 & 72 & 1.440 & 1.080 \\
\hline & \multirow{2}{*}{ onscrearicado } & Inglea Instrumental & 2 & 2 & - & - & - & - & - & - & 4 & 80 & 60 \\
\hline & & Informatica Basica & 2 & 2 & - & - & - & - & - & - & 4 & 80 & 60 \\
\hline & \multicolumn{2}{|c|}{ SUB-TOTAL } & 4 & 4 & 0 & 0 & 0 & 0 & 0 & 0 & 8 & 160 & 120 \\
\hline & Fonmacizo & Inlelsçăo Proflasional & 2 & - & - & - & - & - & - & - & 2 & 40 & 30 \\
\hline & \multirow{4}{*}{ Desomoto } & Desenho TAcnico & - & - & - & 4 & & - & - & - & 4 & 80 & 60 \\
\hline & & Desentho Arquiltetonico e Aubocad & - & - & - & - & 4 & 4 & - & - & 8 & 160 & 120 \\
\hline & & Desenho Estutural & - & - & - & - & - & - & - & 4 & 4 & 80 & 60 \\
\hline & & Perspectiva e Layout & - & - & - & - & - & - & 4 & - & 4 & 80 & 60 \\
\hline & \multirow{9}{*}{ 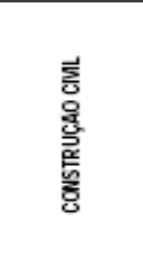 } & Tepografa & - & - & 2 & 2 & - & - & - & - & 4 & 80 & 60 \\
\hline & & Materlas de Conatrug̨ablo I & - & - & - & - & 4 & - & - & - & 4 & 80 & 60 \\
\hline & & Materlass de Construģabo II & - & - & - & - & - & 4 & - & - & 4 & 80 & 60 \\
\hline & & $\begin{array}{l}\text { Ressioncla doz Materiala e } \\
\text { Enruturas }\end{array}$ & - & - & - & - & 4 & 4 & 4 & - & 12 & 240 & 180 \\
\hline & & Insta/açbles Eletricsa & - & - & - & - & - & - & - & 4 & 4 & 80 & 60 \\
\hline & & Ingta/açb̌es Hldro-san taria e Incenclo & - & - & - & - & - & - & 6 & 4 & 10 & 200 & 150 \\
\hline & & Constuçaిం Clv!l I & - & - & - & - & - & 4 & - & - & 4 & 80 & 60 \\
\hline & & Construçäo Civil II & - & - & - & - & - & - & 4 & - & 4 & 80 & 60 \\
\hline & & \begin{tabular}{|l|} 
Mecanica dos Solos \\
\end{tabular} & - & - & - & - & 4 & - & - & - & 4 & 80 & 60 \\
\hline & \multirow{3}{*}{ PLAMEJALETTO } & $\begin{array}{l}\text { Planejamento e Ética na Construçdo } \\
\text { Clvill }\end{array}$ & - & - & - & - & - & - & - & 2 & 2 & 40 & 30 \\
\hline & & Higlene e Segurança do Trabs ho & - & 2 & - & - & - & - & - & - & 2 & 40 & 30 \\
\hline & & \begin{tabular}{|l|l} 
Orçamento e Planejamento \\
\end{tabular} & - & - & - & - & - & - & - & 4 & 4 & 80 & 60 \\
\hline & \multicolumn{2}{|c|}{ SUB-TOTAL } & 2 & 2 & 2 & 6 & 16 & 16 & 18 & 18 & 80 & 1.600 & 1.200 \\
\hline & \multicolumn{2}{|l|}{ Total } & 20 & 20 & 20 & 20 & 20 & 20 & 20 & 20 & 160 & 3.200 & 2.400 \\
\hline & Estagio & Estagio Supervisionado & & & & & & & & & & 640 & 480 \\
\hline
\end{tabular}




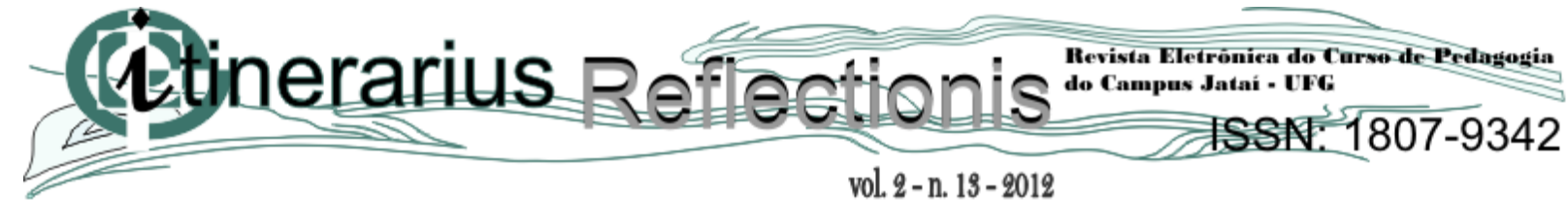

Fonte: Projeto Pedagógico do Curso Técnico Integrado em Edificações na Modalidade PROEJA (CEFET-GO / UnED Jataí)

O projeto do curso foi organizado por disciplinas em regime seriado semestral, veja no quadro 1 , com uma carga horária total de $2.880 \mathrm{~h}$, distribuídas da seguinte maneira: 1.080h para as disciplinas do núcleo comum, 120h para as disciplinas da parte diversificada, 1.200h para as disciplinas de formação profissional. E são acrescentadas, a carga horária das disciplinas, 480 horas para a prática profissional (estágio supervisionado). O período mínimo para conclusão do curso são oito semestres ou quatro anos. Destaca-se, no projeto do curso, que a prática profissional deve permear todo o curso para que aconteça a articulação entre teoria e prática na formação dos alunos. Além disso, de acordo com o projeto, cada período é formado por um conjunto de disciplinas fundamentadas numa visão de áreas afins e interdisciplinares.

\section{Análise e discussão dos dados}

Os dados apresentados a seguir foram coletados, basicamente, por meio de uma pesquisa documental realizada em três fontes: 1) as fichas dos alunos atualmente matriculados no curso Técnico Integrado de Edificações na modalidade PROEJA do Instituto Federal de Goiás - Câmpus Jataí (IFG), as quais foram obtidas no setor de registros acadêmicos da instituição; 2) o Projeto Pedagógico do Curso, obtido junto ao Departamento de Áreas Acadêmicas do campus; 3) os Relatórios de Gestão do Campus, obtidos junto à Direção Geral.

As inscrições no processo seletivo do PROEJA têm oscilado ao longo dos processos seletivos, sendo que a relação candidato/vaga foi de 2,4 no primeiro semestre de 2008 , de 1,8 no primeiro semestre de 2009 , de 1,3 no primeiro semestre de $2010 /$, de 2,6 no primeiro semestre de 2011, de 3,0 no segundo semestre de 2011 e de 2,4 no primeiro semestre de 2012.

O IFG - Campus Jataí, além do curso técnico na modalidade PROEJA, oferece também 4 cursos técnicos integrados ao ensino médio, no turno matutino, quando os alunos em quase sua totalidade possuem idade abaixo de dezoito anos. Nestes cursos também há uma 


\section{(titherarius Reffectionis 201}

oscilação na procura a cada ano, sendo que a relação candidato/vaga foi em média de 2,5 em 2010/1 e 3,0 em 2011/1 e de 2,3 em 2012/1. O curso mais concorrido em 2011/1 foi o de edificações com uma relação candidato/vaga de 3,7. Desta forma, podemos observar que a relação candidato/vaga do curso técnico na modalidade PROEJA é similar à média dos demais cursos integrados de nossa instituição e até mesmo em alguns processos seletivos a relação é superior a algum curso integrado. Verificamos assim, que, no período analisado, há uma concorrência nas vagas oferecidas para o curso técnico integrado de edificações na modalidade PROEJA.

Foram analisadas 84 pastas de alunos das cinco turmas no primeiro semestre de 2012, com estas informações foi realizado um mapeamento dos dados procurando identificar o perfil dos alunos do referido curso.

Destacamos inicialmente que o número de alunos matriculados em cada uma das turmas, no primeiro semestre de 2012, era: 28 alunos no primeiro período, 15 alunos no segundo período, 14 alunos no terceiro período, dez alunos no quinto período e 17 alunos no sétimo período, perfazendo um total de 84 alunos matriculados no curso. Na figura 1 representamos o número de vagas em cada processo seletivo e o número de alunos matriculados em cada período.

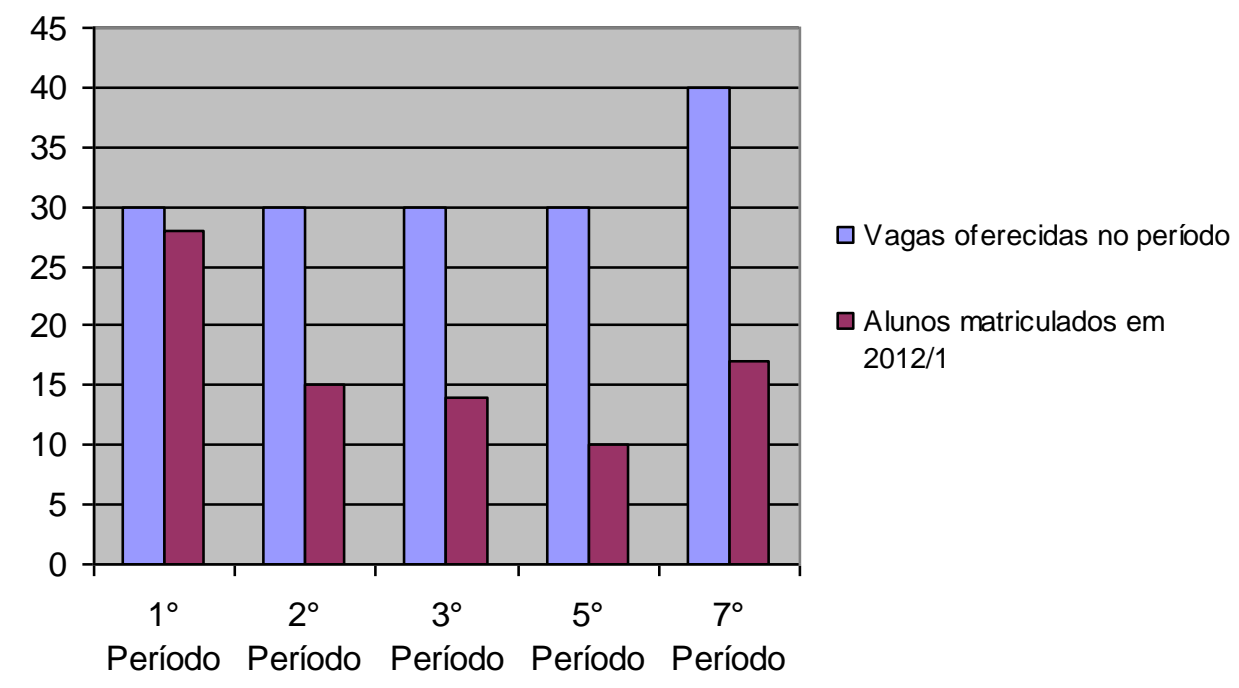

Figura 1 - Número de vagas oferecidas e de alunos matriculados em cada período do curso 


\section{(itinerarius 20}

É possível verificar, por meio dos dados, que em alguns períodos houve um grande número de alunos que não acompanharam o fluxo normal das turmas, pois se se comparar ao número de alunos matriculados no primeiro semestre de 2012 com o número de vagas oferecido em cada um dos processos seletivos de 2009/1 até 2012/1, observa-se uma considerável queda de alunos em cada turma e em 2009 foram oferecidas quarenta vagas, para as demais turmas foram oferecidas trinta vagas.

Assim, temos que de um total de cento e sessenta vagas oferecidas entre 2009 e o primeiro semestre de 2012, somente um total de 84 alunos continuam matriculados, o que nos leva a observar que no mínimo $47,5 \%$ dos alunos evadiram do curso. Se desconsiderarmos os alunos reprovados, verificamos que se tomarmos os períodos $2^{\circ}, 3^{\circ}, 5^{\circ}$ e $7^{\circ}$ pode chegar a uma evasão da ordem de 67\% ao longo dos anos 2009, 2010 e 2011.

Ao analisar os índices de evasão nas duas turmas que ingressaram em 2011, considerando quando (ano do processo seletivo) o aluno ingressou no curso e se continua matriculado nele, ou não. Desta forma, dos 30 (trinta) alunos que ingressaram no curso no segundo semestre de 2011, 15 alunos continuaram matriculados no primeiro semestre de 2012, os demais alunos evadiram do curso, ou seja, foi encontrada uma evasão de cinquenta por cento dos alunos desta turma. Para a turma que ingressou no curso no primeiro semestre de 2011, também com 30 vagas, 14 alunos, um total de $46,7 \%$, evadiram do curso.

Alguns relatos sobre cursos de PROEJA de outras instituições como Bahia também demonstram altos índices de evasão de 40 a 60\% (STOCO, 2010; AZEVEDO e LIMA,2009), que mostraram números próximos aos encontrados em nosso câmpus.

Analisando o gênero do total dos alunos matriculados, foi observado que 55,95\% são do sexo masculino e $44,05 \%$ do sexo feminino, estes valores indicam que as mulheres têm procurado cursos profissionalizantes para ingressar, ou reingressar, no mundo do trabalho de trabalho. Apesar de a área de construção civil ser predominantemente um campo de atuação masculino, tem sido observado um aumento da inserção feminina nesta área. Mas, mesmo com esse aumento, devemos nos lembrar que o número de mulheres ainda é menor que o de homens, principalmente por questões culturais, pois a mulher, na maioria das vezes, necessita deixar os estudos para cuidar dos filhos e da casa. 


\section{(titinerarius 201 \\ vol. 2-n. 13-2012 \\ Revista Eletróniéa do Curso de Pedagogia

Os dados coletados para a faixa etária dos alunos do curso indicam que: 5,95\% dos alunos matriculados possuem entre 18 e 19 anos, $45 \%$ tem entre 20 e 29 anos, 33,3\% tem entre 30 e 39 anos, 14,28\% estão na faixa etária de 40 a 49 anos e 1,2 possuem mais de 50 anos. É de aproximadamente $78 \%$ a faixa etária dos alunos matriculados que estão entre 20 e 39 anos, o que demonstra o importante papel de formação e profissionalização deste público afastado da sala de aula. Pode-se, desta forma, ressaltar o papel social cumprido pela modalidade PROEJA. Destaca-se ainda, que a maioria dos alunos está na faixa etária entre 20 e 29 anos, o que nos mostra uma predominância de alunos jovens buscando uma elevação de escolaridade e qualificação profissional.

De acordo com os dados, $61,8 \%$ dos alunos são solteiros e $38,2 \%$ casados, o que pode nos indicar duas situações, a primeira é que os solteiros têm mais facilidade para permanecer na escola; a segunda é que um número maior de solteiros tem buscado voltar para sala de aula. As duas alternativas consideram as dificuldades em se conciliar os afazeres da vida de casado com os da escola.

Com relação à ocupação dos alunos matriculados, $72 \%$ dos alunos afirmaram trabalhar em período integral e $28 \%$ não estavam trabalhando no momento da matrícula. Como era de se esperar a grande maioria dos alunos do curso da modalidade PROEJA são trabalhadores. O fator trabalho deveria influenciar fortemente a metodologia de ensino adotada pelos docentes que atuam nesta modalidade, o descaso ou despreparo para lidar com esta situação de jovens e adultos trabalhadores pode ser uma das principais causa dos índices de evasão no curso.

Em relação à renda familiar, $48 \%$ dos alunos tem renda entre 1 e 2 salários mínimos, $31 \%$ entre 2 e 3 salários, $18 \%$ entre 3 e 5 salários e apenas $3 \%$ tem renda familiar de 5 a 10 salários. Esses dados revelam que a grande maioria dos alunos do curso PROEJA vem de famílias carentes, buscando uma melhoria não só para si, mas para toda sua família. Para evitar que os alunos desistam do curso por não terem condições mínimas de se manterem como, por exemplo, o pagamento de transporte, o MEC adotou desde 2008 a concessão de auxílios financeiros aos alunos que frequentam regularmente as aulas, estes auxílio em 2012 beneficia o aluno com 120,00 reais em nossa instituição. 


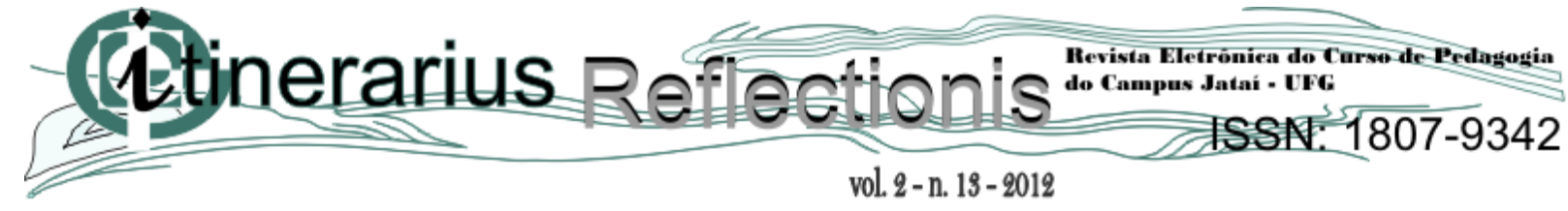

Dois outros dados que nos chamaram a atenção é o número de alunos reprovados e o número de aprovados com dependência. Dos 84 matriculados, 28,5\% foram reprovados, por falta. Analisando os alunos matriculados nas turmas do primeiro e segundo semestre de 2011, percebe-se que nenhum aluno reprovado destas turmas continua no curso. Provavelmente do total de repetentes, poucos voltaram a frequentar o curso. Assim, pode-se perceber que a realidade do curso é o de formar poucos alunos, o que é evidenciado pelos poucos alunos que concluíram o curso nesta modalidade.

Em relação ao número de aprovados com dependência, verifica-se que $23 \%$ do total de alunos estão de dependência, e desses, todos ficaram nas disciplinas de Matemática ou de Física. Estas disciplinas podem estar descontextualizadas da realidade dos cursos de formação de jovens e adultos. O resultado pode indicar, ainda, uma falta de integração destas disciplinas com as disciplinas técnicas do curso.

\section{Considerações finais}

Em nosso trabalho foi analisado o perfil dos alunos matriculados no curso técnico integrado de Edificação, na modalidade PROEJA do IFG - Câmpus Jataí - entre os anos de 2009 e o primeiro semestre de 2012, com o objetivo de conhecer quem são esses alunos que procuram o curso e o índice de evasão no curso.

Foi constatado que, dos ingressantes do curso PROEJA no Instituto Federal de Educação Ciência e Tecnologia de Goiás - Campus Jataí a maioria são jovens entre 20 e 39 anos. Tem predominância em pessoas solteiras e que trabalham integralmente no período diurno.

A pesquisa deixa claro que a origem dos alunos do PROEJA é de baixa renda com relevância na composição da renda familiar, tendo que auxiliar nas despesas da casa. Dessa forma, esses alunos não podem optar entre o trabalho e os estudos, tendo então que conciliar e adaptar a esta situação.

Verifica-se que o principal desafio do PROEJA é viabilizar as condições para o acesso pleno ao direito dos trabalhadores jovens e adultos à educação de qualidade, que 
assegure a elevação da escolaridade, integrada com a formação profissional, numa perspectiva ampla, e que está sendo prejudicado pela necessidade de os alunos conciliar as atividades de sobrevivência, muitas vezes em condições precárias com os tempos de estudo.

Sabe-se que o curso PROEJA é destinado a trabalhadores jovens e adultos, mas fica a dúvida se o curso é pensado realmente para esse público como deveria ser. Analisando o projeto do curso foi possível observar uma extensa carga horária e o formato das aulas. É importante ressaltar a necessidade da integração entre as disciplinas do curso evitando-se a falta de conexão entre as disciplinas propedêuticas e as disciplinas profissionalizantes.

Além disso, o curso tem um período de duração de oito semestres (quatro anos) e ainda um período de 480 horas para a prática profissional fazendo com que alguns alunos não consigam conciliar trabalho e escola já que o curso está muito próximo do curso técnico integrado oferecido nos turnos matutino para aqueles que não possuem defasagem de idade.

Os índices de reprovação nas disciplinas da área das Ciências da Natureza, Matemática e suas Tecnologias, aproximadamente 30\%, nos indicam a necessidade de uma contextualização maior com a área profissionalizante e metodologias de ensino voltadas para a educação de jovens e adultos. Devem ocorrer ações institucionais que promovam diálogos e ações de forma a conhecer as experiências dos educandos no mundo do trabalho, tomando-as como referência de sua visão de mundo e de seus projetos, valorizando seus conhecimentos no processo educativo.

Enfim, espera-se que esses dados possibilitem um melhor conhecimento do público do curso PROEJA do IFG - Câmpus Jataí e que sejam construídas ações que possam contribuir para uma formação profissional de qualidade. Espera-se que o resultado dessa pesquisa possa contribuir para futuros estudos e diagnósticos e possíveis intervenções para a melhoria do curso nesta instituição. 


\section{(1Etinerarius Refiectionis:}

\section{REFERÊNCIAS}

AZEVEDO, Clayte de Paula e LIMA, Ezilda Soares. A evasão escolar no PROEJA do CEFET-MT: Existência e Visão. Educação Profissional: Ciência e Tecnologia. vol. 4. n 2. Jan. - Jun. 2011.

BRASIL. Congresso Nacional. Constituição Federal da República Federativa do Brasil. 5 de outubro de 1988.

BRASIL. Conselho Nacional de Educação. Parecer CNE/CEB n. 11/2001 e Resolução CNE/CEB n. 1/2000. Diretrizes Curriculares para a Educação de Jovens e Adultos. Brasília: MEC, maio 2000.

BRASIL. Decreto n.2208 de 17 de abril de 1997. Regulamenta o $\S 2^{\circ}$ do art.36 e os arts. 39 a 42 da Lei n. ${ }^{\circ}$ 9.394, de 20 de dezembro de 1996, que estabelece as diretrizes e bases da educação nacional.

BRASIL. Decreto n. 5154. 23 de julho de 2004. Regulamenta o $§ 2^{\circ}$ do art. 36 e os arts. 39 a 41 da Lei no 9.394, de 20 de dezembro de 1996, que estabelece as diretrizes e bases da educação nacional

BRASIL. Decreto n. 5.478. 24 junho de 2005. Institui, no âmbito das instituições federais de educação tecnológica, o Programa de Integração da Educação Profissional ao Ensino Médio na Modalidade de Educação de Jovens e Adultos - PROEJA

BRASIL. Decreto n. 5.840. 13 de julho de 2006. Institui, no âmbito federal, o Programa Nacional de Integração da Educação Profissional com a Educação Básica na Modalidade de Educação de Jovens e Adultos - PROEJA

BRASIL. Lei Federal n. 9.394. Lei de Diretrizes e Bases da Educação Nacional. 20 de dezembro de 1996.

BRASIL. Portaria n. 2080. 13 de junho de 2005. Estabelece, no âmbito dos Centros Federais de Educação Tecnológica, Escolas Técnicas Federais, Escolas Agrotécnicas Federais e Escolas Técnicas vinculadas às Universidades federais, as diretrizes para a oferta de cursos de educação profissional de forma integrada aos cursos de ensino médio, na modalidade de educação de jovens e adultos. 
BRASIL. Secretaria de Educação Tecnológica e Profissional (SETEC). Programa Nacional de Integração da Educação Profissional com a Educação Básica na Modalidade de Educação de Jovens e Adultos: Educação Técnica de Nível Médio/Ensino Médio. Documento Base. Brasília, DF. 2007.

CASTRO, Mad'Ana Desirée Ribeiro; MACHADO, Maria Margarida e ALVES, Miriam Fábia. O Proeja como desafio na política de educação voltada a jovens e adultos trabalhadores. In: Machado, Maria Margarida e Oliveira, João Ferreira de (Orgs.). A formação integrada do trabalhador: desafios de um campo em construção. São Paulo. Xamã, 2010.

FREIRE, Paulo. Pedagogia da Autonomia: saberes necessários à prática educativa. São Paulo: Paz e Terra, 1996.

FRIGOTTO, Gaudêncio. Concepções e mudanças no mundo do trabalho e o ensino médio. 2008. Disponível em: http://www.ia.ufrrj.br/ppgea/conteudo/conteudo-2008-2/EducacaoMII/2SF/2-Frigotto2008.pdf. Acesso em: 08 ago. 2012.

Projeto de Curso. Curso Técnico de Nível Médio Integrado do EJA. Edificações - PROEJA. Jataí/Goiás, 2005.

STOCO, Heloisa Pancieri. A educação de jovens e adultos trabalhadores no PROEJA: acesso e permanência no CEFET-BA. Revista Eletrônica Multidisciplinar Pindorama do Instituto Federal de Educação, Ciência e Tecnologia da Bahia. 2010. Disponível em: http://www.revistapindorama.ifba.edu.br/files/Heloisa\%20Pancieri\%20Stoco\%20IFBA.pdf. Acesso em: 15 set. 2012. 